\title{
FORMAÇÃO INICIAL DE PROFESSORES DE EDUCAÇÃO FÍSICA E INCLUSÃO DE ALUNOS COM NECESSIDADES EDUCATIVAS ESPECIAIS
}

\author{
Barbara Darbem Zancheta, Wagner Aparecido Caetano, Janaína Pereira Duarte Bezerra \\ Universidade do Oeste Paulista - UNOESTE, Curso de Educação Física, Presidente Prudente, SP. E-mail: \\ barbara.zanqueta@gmail.com
}

\begin{abstract}
RESUMO
O tema inclusão está cada vez mais presente nos dias de hoje. Dentro disso, o profissional de Educação Física está recebendo cada vez mais a responsabilidade de ministrar aulas para alunos com ou sem necessidades educativas especiais. $O$ presente estudo teve por objetivo investigar as lacunas da formação inicial dos profissionais de Educação Física sobre o tema inclusão dentro do ambiente escolar, através de uma análise de grade curricular onde encontramos defasagem no número de disciplinas relacionas ao tema inclusão. O procedimento metodológico adotado possibilitou inferirmos que há lacunas pontuais, quanto ao tema formação dos professores de educação física, que necessitam de uma reestruturação nas grades curriculares dos cursos de graduação em Educação Física na cidade de Presidente Prudente.
\end{abstract}

Palavras-chave: Inclusão, Educação Inclusiva, Educação física, Formação Inicial, Grade Curricular.

\section{INITIAL TRAINING OF TEACHERS OF PHYSICAL EDUCATION AND INCLUSION OF STUDENTS WITH SPECIAL EDUCATIONAL NEEDS}

\begin{abstract}
The theme of inclusion is increasingly present today. In addition, the professional of Physical Education is getting more and more responsibility to teach classes for students with and without special educational needs. This study aimed to investigate the shortcomings of initial training of physical education professionals on the subject of inclusion within the school environment, through a curriculum analysis where we lag in the number of disciplines relacionas the theme inclusion. The methodological procedure adopted enabled infer that there are specific gaps on the subject training of physical education teachers, who need a restructuring in the curricula of undergraduate courses in Physical Education in the city of PresidentePrudente. Keywords: Inclusion, Inclusive Education, PhysicalEducation, Initial Training, Curriculum.
\end{abstract}




\section{INTRODUÇÃO}

Nas últimas décadas a Educação Física vem ganhando maior significado dentro das instituições escolares, principalmente após a promulgação do Art. 26 da Lei de Diretrizes e Bases no 9394/1996 (LDB) que aponta a Educação Física como disciplina obrigatória componente curricular do ensino fundamental e médio. Essa condição fomentou diferentes discussões acerca da disciplina em questão no contexto educacional, momento em que foi possível constatar diferentes abordagens culminando no rompimento do academicismo exclusivamente relacionando ao esporte ou à prática dele ampliando as temáticas, os objetivos e possibilidades práticas pedagógicas se tornando uma disciplina capaz de contribuir com relevância à formação do ser humano em suas dimensões.

Mesmo com essas condições históricas, que modificaram o contexto e características da Educação Física, esta não perdeu sua perspectiva acerca da corporeidade, pelo contrário, agregou a esse corpo diferentes condicionamentos históricos, sociais, políticos e econômicos, além de não só reconhecer seu novo campo de estudo como se legitimou a pensar sobre eles. Dentre a grande massa de "novos temas", citamos neste trabalho a preocupação com a inclusão.

Silva (2011) destaca que as aulas de Educação Física deve ser um encontro de manifestações culturais, levando em conta toda bagagem motora e o seu desenvolvimento.

Oliveira (1986) explica que:

[...] a educação física apesar de ser uma atividade essencialmente prática, pode oferecer oportunidades para a formação do homem consciente, crítico, sensível à realidade que o envolve.(OLIVEIRA,1986, p.97).

Para o Parâmetro Curricular Nacional (PCN) de Educação Física, o professor deve buscar meio para garantir a vivencia prática da experiência corporal, com base em sua realidade social e pessoal. Fato é que essa "realidade social" ainda (ou sempre) está em construção. Essa construção perpassa todas as áreas da existência humana.

Maciel (2000) relata que "Hoje, no Brasil, milhares de pessoas com algum tipo de deficiência tais como a física, visual, auditiva, entre outras estão sendo discriminadas nas comunidades em que vivem ou sendo excluídas do mercado de trabalho" (MACIEL, 2000, p. 51). Maria Luisa Sprovieri Ribeiro, professora assistente e doutora da Universidade de São Paulo, prolonga essa discussão relacionando o tema à educação, ressaltando que "[...] a perspectiva de inclusão exige o repensar das condições da prática docente e de suas dimensões, bem como de suas repercussões na organização curricular e na avaliação" (RIBEIRO, 2003, p.41).

Segundo Cidade e Freitas (apud, SASSAKI, 1997, p.01), “a inclusão é a modificação da sociedade como pré-requisito para que pessoa com necessidades especiais possa buscar seu desenvolvimento e exercer a cidadania". Tais ideias se aproximam de afirmativas em prol da consciência inclusiva às unidades educativas.

O âmbito escolar está cada vez mais diversificado, ou seja, é construído sob a multiplicidade de culturas, gêneros, deficiências e relações socioeconômicas, por isso, a escola precisa abordar com significado e relevância essas novas e reais perspectivas, abrangendo a relação entre alunos e, pensando, repensando, em questões estruturais e corpo docente.

Assim, Cidade e Freitas (2002), afirmam que ocorrem muitas discussões sobre a inserção de alunos portadores de necessidades educativas especiais, gerando polêmica de como realizar a inclusão de forma coerente.

É fato que estas discussões se apresentam como desafios educacionais do novo século, XXI. Na visão de Toloi (2015, p.16), "as diversas mudanças ocorridas nas ultimas décadas no sistema educacional aumentaram a complexidade de ações inclusivas e apresentam novos desafios para a Educação". 
Em nosso estudo, o locus desta pesquisa é a escola, ou a Educação Física Escolar. Uma das grandes transformações, vividas ainda como desafios na contemporaneidade é a efetivação de alguns dizeres da última LDB (9.394/96). Nosso trabalho investigou uma dessas alusões da lei: a inclusão.

A hipótese que sustenta esse trabalho é a de que há, na formação de professores de Educação Física, lacunas que ainda implicam obstáculos para a criação de ações afirmativas que sejam capazes de realmente incluir alunos que possuem algum tipo de necessidade especial. Embora haja desde 1987, alusões a conteúdos formativos para a graduação, que vivem preparar o professor de Educação Física. (FIORINI, 2011), para as práticas de atividades inclusivas, pensamos que tais práticas e atividades ainda não se materializaram.

Não é de hoje que se discute a formação de professores no sistema de educação. Gatii (2010, p.16) nos mostra que "A questão sobre formação de professores acaba surgindo com o ensino das "primeiras letras" apenas em alguns cursos no final do século XIX, com a criação das Escolas Normais".

Para Saviani (2009), a questão do preparo de professores no Brasil surge após a independência logo após o processo de organização para instrução popular. Segundo Antônio Nóvoa, "a formação deve estimular uma perspectiva crítico-reflexiva, que forneça aos professores os meios de um pensamento autônomo e que facilite as dinâmicas de auto-formação participada" (NÓVOA, 1992, p.13). Sustenta ainda que a formação não deve ser baseada na quantidade de cursos feitos pelos docentes, mas sim na busca de melhorias em suas práticas pedagógicas que visualizem seu comprometimento sobre seu próprio desenvolvimento pessoal.

Toloi (2015) ratifica que, no contexto da formação profissional dos professores atuantes na rede escolar, é necessário mostrar a importância de superar obstáculos impostos pela falta de capacitação desse profissional que está presente nas escolas do Brasil.

Assim sendo, o objetivo deste trabalho foi identificar as barreiras e lacunas existentes na formação de professores de Educação Física sobre o tema "inclusão de crianças com necessidades educativas especiais" a partir da verificação e analise das grades curriculares dos cursos de Educação Física (graduação) existentes no município de Presidente Prudente com o intuito de analisar os conteúdos e disciplinas correspondentes ao tema "inclusão de crianças com necessidades especiais".

\section{METODOLOGIA}

A abordagem metodológica adotada seguiu os preceitos da uma pesquisa de caráter qualitativo. Referente a isso, Menga \& André (1986) esclarecem que esta enquadra-se na modalidade de reconhecimento da realidade de seus sujeitos, observação cuidadosa, estruturada e sistemática, garantindo um olhar rigoroso sobre o campo de pesquisa e a descrição cuidadosa dos elementos nele identificados pelo pesquisador.

Para melhor debater as ideias sobre acerca da inclusão, fora utilizado artigos publicados em periódicos específicos da área de Educação Física Escolar. Sendo assim, é pertinente que, para esclarecer a metodologia adotada neste trabalho, com os dizeres de Patton (1999 apud AlvesMazzotti, 1999, p. 132) que discorre sobre a dimensão de campo da pesquisa que contém dados qualitativos:

[...] descrições detalhadas de situações, eventos, pessoas, interações e comportamentos observados; citações literais do que as pessoas falam sobre suas experiências, atitudes, crenças e pensamentos; trechos ou íntegras de documentos, correspondências, atas ou relatórios de casos (PATTON apud ALVES-MAZZOTTI, 1999, p. 132). 
Também foi realizada análise das grades curriculares dos cursos de graduação em Educação Física ofertados na cidade de Presidente Prudente, por meio de uma análise documental.

É importante destacar que há no município de Presidente Prudente 2 (duas) universidades e 1 (uma) faculdade totalizando 3 (três) instituições que oferecem o curso de Educação Física. Consultamos suas respectivas grades, disponibilizadas no site, que está aberta ao público, e pelo nome de cada disciplina, o intuito foi visualizar o trato que se dá ao tema de inclusão. Relembrando que essa problemática tornou-se obrigatória à reflexão escolar desde a última década do século passado.

A análise das grades curriculares dos cursos de Educação Física teve como finalidade a identificação da disciplina que contemple o tema inclusão, o termo no qual a disciplina é ofertada e a quantidade de horas/aula ofertadas a tais disciplinas.

\section{RESULTADOS}

As grades curriculares dos cursos de graduação em Educação Física na cidade de Presidente Prudente contém as seguintes ementas:

Tabela 01. Ementas da grade curricular

\begin{tabular}{|c|c|c|c|}
\hline Universidades & CURSO A & CURSO B & CURSO C \\
\hline Disciplina(s) & $\begin{array}{l}\text { - Educação Física e } \\
\text { Esporte para pessoas } \\
\text { com deficiência; } \\
\text { - Língua Brasileira de } \\
\text { Sinais - Libras. }\end{array}$ & $\begin{array}{l}\text { - Práticas curriculares } \\
\text { em Educação Física } \\
\text { para pessoas com } \\
\text { deficiência; } \\
\text { - Educação Física para } \\
\text { pessoas com } \\
\text { deficiência. }\end{array}$ & $\begin{array}{l}\text { - Língua Brasileira de } \\
\text { sinais - Libras. }\end{array}$ \\
\hline Termo & 5ㅇ e 6은 & 4음 ano & 5음 \\
\hline Total de Horas & $120 \mathrm{~h}$ Semestrais & $90 \mathrm{~h} \mathrm{Semestrais}$ & $80 \mathrm{~h}$ Semestrais \\
\hline
\end{tabular}

Fonte: elaborada pela pesquisadora.

Encontramos uma defasagem no que se trata ao número de disciplinas relacionadas ao tema inclusão. O curso de Educação Física tem uma carga horária intensa e quando se faz relação com disciplinas sobre inclusão, parece não haver grande importância sobre o tema, levando em conta apenas o nome das ementas.

Pensando nas outras disciplinas abordadas ao longo do curso, como esportes coletivos, individuais ou não convencional, ginástica, dança entre outras será que o tema inclusão está relacionado ao discurso e prática dos professores das universidades? Pois o número de disciplinas é expressivo e permitem a menção, via interdisciplinaridade, de temas transversais, entre eles a "inclusão".

Tabela 02. Número de disciplinas relacionadas ao curso de Educação Física

\begin{tabular}{l|l|l|lr}
\hline Universidade A & Universidade B & Universidade C \\
\hline 43 matérias ofertadas & 60 matérias ofertadas & 42 matérias ofertadas \\
obrigatórias, sendo 2 & obrigatórias, sendo 2 2 & $\begin{array}{l}\text { obrigatórias, sendo 1 } \\
\text { específica ao tema } \\
\text { específicas ao tema } \\
\text { inclusão. }\end{array}$ & $\begin{array}{l}\text { específicas ao tema } \\
\text { inclusão. }\end{array}$ inclusão. \\
\hline
\end{tabular}

Fonte: elaborada pela pesquisadora. 
Os resultados evidenciam que as disciplinas relacionadas ao tema inclusão constam menos de $2 \%$ do total de disciplinas analisadas. Diante dessa análise, percebemos uma necessidade de se trabalhar o tema inclusão no ambiente acadêmico.

\section{DISCUSSÃO}

Considerando todo o processo histórico da Educação Física, onde existia a prática não inclusiva favorecendo os "melhores", parece que ainda temos vestígios do que era proposto. Não devemos pensar só nas disciplinas, mas também nos conteúdos e reflexões propostos em toda a formação acadêmica, não deixando isso para o último ano/termo, pois no ambiente escolar espera-se que professores saibam ao menos lidar com as situações.

Analisando toda a perspectiva da Educação Física escolar, os benefícios, a importância motora e social tem como base a necessidade do professor bem formado e informado sobre esse público alvo que só cresce nas escolas. Se eu não tenho um professor, além da equipe gestora, que saiba lidar com diversas situações, como posso falar em escola inclusiva?

Pensando em todos esses aspectos que permeiam a escola regular, com a chegada dos alunos com necessidades especiais, precisamos de uma reestruturação da grade curricular, pensando nos benefícios que isso trará ao profissional e aluno que estará na escola aguardando o aprendizado e desenvolvimento.

\section{CONCLUSÃO}

Esse trabalho possibilitou entender que as disciplinas relacionadas ao tema inclusão presentes nas grades de cursos de Educação Física além de totalizar menos de $2 \%$ de disciplinas analisadas, não contemplam o conteúdo voltado à inclusão já que se encontram amparadas em maior parte nas disciplinas que tratam de propor práticas a partir do esporte adaptado para os estudantes, o que a nosso ver não coloca o professor recém formado em contato com elementos referentes à inclusão.

Entendemos que a Educação Física como componente curricular, que é importante e necessário para que a criança/jovem se desenvolva nos seus aspectos físico, intelectual e social, também tem como objetivo possibilitar a inclusão de todos independente de suas impossibilidades, porém para que isso se efetive é necessário que o professor atue como mediador desse processo e sendo responsável pela construção do saber e do ser social, mas com direcionamentos advindos da formação inicial que como já evidenciamos encontra-se em defasagem.

Vale destacar que com a chegada de Estudantes Público Alvo da Educação Especial na escola de ensino regular, os professores se veem sem condições e sem conhecimento para desenvolver práticas pedagógicas, que favoreçam de forma efetiva que esse aluno se mantenha na escola, considerando acesso- permanência e aprendizado.

E no que se trata ao aprendizado, precisamos de professores bem capacitados, com uma formação inicial concernente com a atuação frente ao processo de inclusão no interior da instituição escolar.

\section{REFERÊNCIAS}

ALVES, M, A. J. O método nas ciências sociais. In: ALVES-MAZZOTTI, J. A.; GEWANDSZNAJDER, F. O método nas ciências naturais e sociais: pesquisa quantitativa e qualitativa. 2. ed. São Paulo: Pioneira, 1999.

BRASIL, Lei N.ㅇ 13.146 DE 06 de julho de 2015, Institui a Lei Brasileira de Inclusão da Pessoa com Deficiência (Estatuto da Pessoa Com Deficiência) disponível em: 
17/jul/2016.

BRASIL, Lei N.9394, de 20 de dezembro de 1996, Estabelece as Diretrizes e Bases da Educação Nacional, disponível em: http://www.planalto.gov.br/ccivil 03/leis/L9394.htm. Acesso em $17 / \mathrm{jul} / 2016$.

BRASIL,Parâmetros Curriculares Nacionais Educação física / Secretaria de Educação Fundamental. - Brasília :MEC/SEF,1997. 96p

CIDADE, R. E. A, FREITAS, P. Educação Física e Inclusão: considerações sobre a prática pedagógica na escola. Integração (Brasília), Brasília, v. Ano 14,p. 26-30, 2002.

FIORINI, S. L. M. Concepção do professor de Educação Física sobre a inclusão do aluno com deficiência.2011. 145 f. Dissertação (Mestrado em Educação) - Faculdade de Filosofia e Ciências, da Universidade Julio de Mesquita Filho, Campus de Marília.

GATTI, B.A. Formação de professores no Brasil: características e problemas, Educação \& Sociedade, Campinas, v.31, n. 113, pp.1355-1379, out/dez, 2010. https://doi.org/10.1590/S010173302010000400016.

MACIEL, M.R.C, Portadores de deficiência: a questão da inclusão social. São Paulo em Perspectiva, São Paulo,vol.14, n.2, 2000.

MENGA, L.; ANDRE, M. E. D. A. Pesquisa em educação: abordagens qualitativas. São Paulo: EPU, 1986.

NOVOA, A. Formação de professores e Formação docente, disponível em: http://repositorio.ul.pt/bitstream/10451/4758/1/FPPD A Novoa.pdf. Acesso em: 17/jul/2016.

OLIVEIRA.M.V. O que é Educação Física. 19. ed.São Paulo: Brasiliense,1986.v.1.112p.

RIBEIRO, M.L.S, Perspectiva da Escola Inclusiva: Algumas Reflexões in (2003) "Educação Especial: do querer ao fazer" Org. Maria Luiza Sprovieri Ribeiro, Roseli Cecília Rocha de Carvalho Baumel

SASSAKI, Romeu K. Inclusão. Construindo uma sociedade para todos. Rio de Janeiro, Ed. WVA 1997 https://doi.org/10.1590/S1413-24782009000100012.

SAVIANI, D, Formação de professores: aspectos históricos e teóricos do problema no contexto brasileiro*. Revista Brasileira de Educação, v.14, n.40, jan/abr.2009

SILVA, L.J.E, A prática do professor de Educação Física Escolar: Perspectivas de Inclusão. 2011. 123 f. Dissertação (Mestrado em Educação) - Universidade do Oeste Paulista, Presidente Prudente.

TOLOI, G.G, Formação de Professores de Educação Física para Inclusão Educacional usando Tecnologia Assistiva,2015. 212 f, Tese (Doutorado em Educação) - Universidade Julio Mesquita Filho, campus de Marília. 